\title{
Combined Experimental and Computational Study of the Thermochemistry of Methylpiperidines
}

\author{
Manuel A. V. Ribeiro da Silva,* Joana I. T. A. Cabral, Paula Gomes, and José R. B. Gomes \\ Centro de Investigação em Química, Department of Chemistry, Faculty of Science, University of Porto, \\ Rua do Campo Alegre, 687, P-4169-007 Porto, Portugal \\ risilva@fc.up.pt
}

Received November 30, 2005

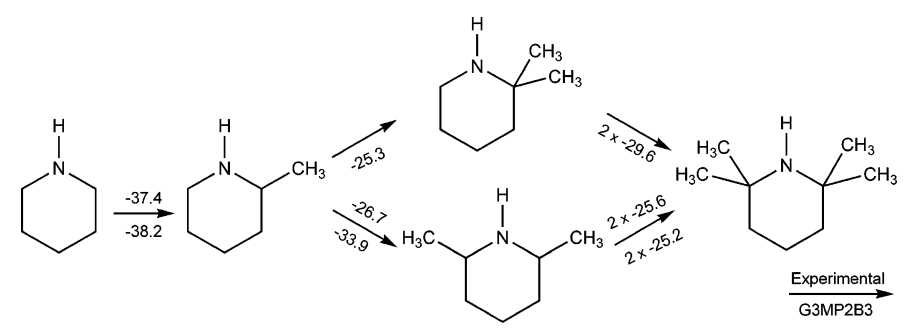

To understand the influence of the methyl group in the stability and conformational behavior of the piperidine ring, the standard $\left(p^{0}=0.1 \mathrm{MPa}\right)$ molar enthalpies of formation of 1-methylpiperidine, 3-methylpiperidine, 4-methylpiperidine, 2,6-dimethylpiperidine, and 3,5-dimethylpiperidine, both in the liquid and in the gaseous states, were determined at the temperature of $298.15 \mathrm{~K}$. The numerical values of the enthalpies of formation in the liquid and in the gaseous state are, respectively, $-(95.9 \pm 1.6)$ and $-(59.1 \pm 1.7) \mathrm{kJ} \cdot \mathrm{mol}^{-1}$ for 1-methylpiperidine; $-(123.6 \pm 1.4)$ and $-(79.2 \pm 1.6) \mathrm{kJ} \cdot \mathrm{mol}^{-1}$ for 3-methylpiperidine; $-(123.5 \pm 1.5)$ and $-(82.9 \pm 1.7) \mathrm{kJ} \cdot \mathrm{mol}^{-1}$ for 4-methylpiperidine; $-(153.6 \pm$ $2.1)$ and $-(111.2 \pm 2.2) \mathrm{kJ} \cdot \mathrm{mol}^{-1}$ for 2,6-dimethylpiperidine; and $-(155.0 \pm 1.7)$ and $-(105.9 \pm 1.8)$ $\mathrm{kJ} \cdot \mathrm{mol}^{-1}$ for 3,5-dimethylpiperidine. In addition, and to be compared with the experimental results, theoretical calculations were carried out considering different ab initio and density functional theory based methods. The standard molar enthalpies of formation of the four isomers of methylpiperidine and of the 12 isomers of dimethylpiperidine have been computed. The G3MP2B3-derived numbers are in excellent agreement with experimental data, except in the case of 2,6-dimethylpiperidine for which a deviation of $9 \mathrm{~kJ} \cdot \mathrm{mol}^{-1}$ was found. Surprisingly, the DFT methods fail in the prediction of these properties with the exception of the most approximated SVWN functional.

\section{Introduction}

The conformation of six-membered heterocycles has been studied over a long period by a varied number of techniques, but less attention has been given to their stability. In the past years, there has been a tendency to overcome this lack of information, and some studies were carried out on the thermochemical properties of some of these compounds, namely oxane,${ }^{1-3}$ thiacyclohexane ${ }^{4}$ and derivatives. In the case of the

* Corresponding author. Phone: +35122 6082 821. Fax: +351 226082 822.

(1) Pell, A. S.; Pilcher, G. Trans. Faraday Soc. 1965, 61, 71

(2) Snelson, A.; Skinner, H. A. Trans. Faraday Soc. 1961, 57, 2125.
$N$-containing heterocycles, a few experimental works may be found in the literature concerning the thermodynamic properties of piperidine and alkylpiperidines. ${ }^{5-10}$ The small number of

(3) Cass, R. C.; Fletcher, S. E.; Mortimer, C. T.; Springhall, H. D.; White, T. R. J. Chem. Soc. 1958, 1406.

(4) Roux, M. V.; Temprado, M.; Jiménez, P.; Dávalos, J. Z.; Notario, R.; Guzmán-Mejía, R.; Juaristi, E. J. Org. Chem. 2003, 68, 1762.

(5) Good, W. J. Chem. Eng. Data 1972, 17, 28.

(6) Bedford, A. F.; Beezer, A. E.; Mortimer, C. T. J. Chem. Soc. 1963, 2039.

(7) Procházka, M.; Krestanova, V.; Palecek, M.; Pecka, K. Collect. Czech. Chem. Commun. 1970, 35, 3813.

(8) Messerly, J. F.; Todd, S. S.; Finke, H. L.; Good, W. D.; Gammon, B. E. J. Chem. Thermodyn. 1988, 20, 209. 
studies concerning the stability of this class of molecules contrasts with the biologically important aspects of piperidine derivatives. ${ }^{11}$ The piperidine motif may be found in drugs or drug candidates with interesting and promising therapeutical use. This structural unit is a key component of successful antiParkinson's agents and other drugs with antipsychotic, antiviral, metabolic, immunomodulatory, antiinflammatory, and cerebrovascular activity. ${ }^{12-17}$ Recently, some piperidine derivatives were found to have important activity for the treatment of cocaine abuse. ${ }^{18}$

The works published in the literature concerning the thermochemistry of piperidine and its derivatives are summarized below. First, Bedford et al. ${ }^{6}$ used a twin-valve bomb to measure the energy of combustion of liquid piperidine. Further, these authors determined the enthalpy of formation of piperidine by incorporating the enthalpy of vaporization, reaching the value $-(48.83 \pm 2.55) \mathrm{kJ} \cdot \mathrm{mol}^{-1}$. The enthalpy of combustion and of formation in the condensed phase was measured using a bomb calorimeter for a series of $N$-substituted piperidines by Procházka and co-workers. ${ }^{7}$ These authors aimed to obtain the hydrogenation heat and delocalization energy in this kind of compound. Later, Good and co-workers ${ }^{5,8}$ used a combination of different techniques, namely, rotating-bomb combustion and adiabatic calorimetries to obtain the enthalpies of combustion, vaporization, and formation of piperidine and 2-methylpiperidine. These authors confirmed the previous value of Bedford and collaborators. The gas-phase enthalpies of formation determined by Good et al. are $-(47.15 \pm 0.63)$ and $-(84.5 \pm 1.1) \mathrm{kJ} \cdot \mathrm{mol}^{-1}$ for piperidine and 2-methylpiperidine, respectively. In another work devoted to the thermochemistry of the 2,2,6,6-tetramethylpiperidine compound, ${ }^{19}$ Verevkin reached a much more negative value for the enthalpy of formation of this compound in the gas phase, $-(162.4 \pm 2.1) \mathrm{kJ} \cdot \mathrm{mol}^{-1}$, indicating significant stabilization of piperidine even with the presence of four bulky ligands near the nitrogen atom lone pair. In that work, Verevkin determined the enthalpy of vaporization of this compound and used the enthalpy of formation in the liquid phase, $-(206.9 \pm$ 2.0) $\mathrm{kJ} \cdot \mathrm{mol}^{-1}$, published earlier by Pilcher et al. ${ }^{9}$ More recently, Verevkin studied the effect of different substituents, such as methyl, ethyl, propyl, and so forth, attached to the nitrogen atom of piperidine. ${ }^{10}$ It is also possible to find in the literature a theoretical work devoted to the calculation of the enthalpies of formation and proton affinities for aziridine, azeditine, pyrro-

(9) Suradi, S.; Hacking, J. M.; Pilcher, G.; Gümrük, I.; Lappert, M. F. J. Chem. Thermodyn. 1981, 13, 857.

(10) Verevkin, S. P. Struct. Chem. 1998, 9, 113.

(11) Johnson, M. R.; Milne, G. M. In Burger's Medical Chemistry, 4th ed.; Wolff, M. E., Ed.; Wiley: New York, 1981; Part III, p 699.

(12) Onishi, Y.; Oguro, M.; Kizaki, H. Cancer Lett. 1998, 127, 147.

(13) Yang, L.; Morrielo, G.; Patchett, A. A.; Leung, K.; Jacks, T.; Cheng, K.; Schleim, K. D.; Feenet, W.; Chan, W. W.-S.; Chiu, S.-H. L.; Smith, R. G. J. Med. Chem. 1998, 41, 2439.

(14) Klockgether, T.; Wüllner, U.; Steinbach, J. P.; Petersen, V.; Turski, L.; Löschmann, P.-A. Eur. J. Pharmacol. 1996, 301, 67.

(15) Fletcher, S. R.; Burkamp, F.; Blurton, P.; Cheng, S. K. F.; Clarkson, R.; O'Connor, D.; Spinks, D.; Tudge, M.; Niel, M. B.; Patel, S.; Chapman, K.; Marwood, R.; Shepheard, S.; Bentley, G.; Cook, G. P.; Bristow, L. J.; Castro, J. L.; Hutson, P. H.; MacLeod, A. M. J. Med. Chem. 2002, 45, 492.

(16) Johnston, G. A. R. Curr. Top. Med. Chem. 2002, 2, 903.

(17) Köhler, H.; Rodrigues, S. P.; Maurelli, A. T.; McCormick, B. A. J. Infect. Dis. 2002, 186, 1122.

(18) Kozikowski, A. P.; Araldi, G. L.; Boja, J.; Meil, W. M.; Johnson, K. M.; Flippen-Anderson, J. L.; George, C.; Saiah, E. J. Med. Chem. 1998, 41, 1962.

(19) Verevkin, S. P. J. Chem. Thermodyn. 1997, 29, 891. lidine, and piperidine molecules. ${ }^{20}$ In that work, the optimization of the molecular structures was carried out at both ab initio and DFT levels of theory. Surprisingly, these authors only considered in their calculations the piperidine isomer with $\mathrm{NH}$ in an axial conformation, which was found to be less stable than the conformation with equatorial $\mathrm{NH}$ piperidine. ${ }^{21-23} \mathrm{In}$ the work of Vayner and Ball, ${ }^{20}$ comparison between computational and experimental enthalpies of formation show that the B3LYP/6-311G** result for aziridine is in close agreement with experimental data, while the MP2/6-31G* approach performs better for pyrrolidine and piperidine. Further, the SVWN/6-31G* method was found to be the best approach for the calculation of proton affinities, at least for the four compounds mentioned in that work.

As referred to above, the importance of piperidine-based compounds and the effects in their properties due to different attached groups have motivated this study. In fact, it was found recently that the incorporation of methyl groups in the piperidine heterocyclic ring changes the properties of piperidine analogues of D-galactose. ${ }^{24}$

In the present work, the standard molar energies of combustion of 1-methylpiperidine, 3-methylpiperidine, 4-methylpiperidine, 2,6-dimethylpiperidine, and 3,5-dimethylpiperidine, all compounds in liquid state, were measured by static bomb combustion calorimetry. Moreover, the standard molar enthalpies of vaporization of these five compounds were determined by Calvet microcalorimetry, using for these liquids a technique similar to that described for sublimation of solids by Skinner et al. ${ }^{25}$ Combining the results measured by these two techniques, the standard molar enthalpies of formation, at $T=298.15 \mathrm{~K}$ in the gaseous state, were derived. In parallel, the gas-phase enthalpies of formation of piperidine, the four methylpiperidines, and of the 12 dimethylpiperidines were estimated from the computed enthalpies of selected working reactions (substitution or atomization; different theoretical approaches) and previous experimental data for all species included in those reactions except those in which we are interested.

\section{Results}

Combustion Calorimetry Results. Table 1 presents, for each compound, the individual values of the experimental determinations of the massic energies of combustion, $\Delta_{\mathrm{c}} u^{\mathrm{o}}$, together with their mean and standard deviations. Detailed results for all combustion experiments of each compound are given in the Supporting Information (Tables S1-S5).

Microcalorimetry Results. Results of the microcalorimetric determination of the enthalpies of vaporization are given in the Supporting Information (Table S6). The enthalpies of vaporization at temperature $T$ correspond to the mean values of five experiments with uncertainties given by their standard deviations. The standard molar enthalpies of vaporization, at $T=$

(20) Vayner, E.; Ball, D. W. J. Mol. Struct.: THEOCHEM 2000, 496, 175

(21) Parkin, J. E.; Buckley, P. J.; Costain, C. C. J. Mol. Struct. 1981, $89,465$.

(22) Kassaee, M. Z.; Haerizade, B. N.; Hossaini, Z. S. J. Mol. Struct. THEOCHEM 2005, 713, 245.

(23) Scott, D. W. J. Chem. Thermodyn. 1971, 3, 640

(24) Shilvock, J. P.; Nash, R. J.; Watson, A. A.; Winters, A. L.; Butters, T. D.; Dwek, R. A.; Winkler, D. A.; Fleet, G. W. J. J. Chem. Soc., Perkin Trans. 1 1999, 2747.

(25) Adedeji, F. A.; Brown, D. L. S.; Connor, J. A.; Leung, W. L.; PazAndrade, I. M.; Skinner, H. A. J. Organomet. Chem. 1975, 97, 221. 
TABLE 1. Individual Values of the Massic Energy of Combustion, $\Delta_{\mathrm{c}} \boldsymbol{u}^{\mathbf{0}}$, for All Compounds at $T=298.15 \mathrm{~K}$

\begin{tabular}{ccccc}
\hline 1-methyl & 3-methyl & 4-methyl & 2,6-dimethyl & 3,5-dimethyl \\
\hline \multicolumn{5}{c}{$-\Delta_{\mathrm{c}} u^{\mathrm{o} /(\mathrm{J} / \mathrm{g})}$} \\
41517.30 & 41226.88 & 41219.19 & 41858.61 & 41823.25 \\
41490.78 & 41225.52 & 41221.75 & 41866.63 & 41830.76 \\
41515.69 & 41228.35 & 41234.49 & 41832.29 & 41825.24 \\
41495.94 & 41224.84 & 41223.47 & 41825.47 & 41837.88 \\
41505.24 & 41220.96 & 41219.63 & 41832.17 & 41834.24 \\
41501.68 & 41223.67 & 41236.08 & 41850.61 & 41829.97 \\
& & 41226.48 & 41828.65 & \\
& 41229.47 & & \\
$41504.4 \pm 4.3$ & $41225.0 \pm 1.0$ & $41226.3 \pm 2.3$ & $41842.1 \pm 6.2$ & $41830.2 \pm 2.2$
\end{tabular}

298.15 K, are given in Table 2. The uncertainties associated with these values are twice the standard deviation of the mean and include the uncertainty associated with the calibration procedure.

Enthalpies of Formation. Table 2 lists, for each compound, the derived standard molar values for the energy $\left(\Delta_{\mathrm{c}} U_{\mathrm{m}}^{\mathrm{o}}\right)$ and enthalpy $\left(\Delta_{\mathrm{c}} H_{\mathrm{m}}^{\mathrm{o}}\right)$ of combustion reaction, at $T=298.15 \mathrm{~K}$, in a static combustion bomb, under oxygen at $p=3.04 \mathrm{MPa}$, in the presence of $1.00 \mathrm{~cm}^{3}$ of water, yielding $\mathrm{CO}_{2}(\mathrm{~g})$ and $\mathrm{H}_{2} \mathrm{O}(\mathrm{l})$.

The uncertainties of standard molar energies and enthalpies of combustion are twice the final overall standard deviation of the mean and include the uncertainties in calibration as well as the respective uncertainties of auxiliary compounds used. Finally, the standard molar enthalpies of formation of all compounds, in gaseous state and at $T=298.15 \mathrm{~K}$, are also given in Table 2 .

Molecular Geometries. The gas-phase structure of piperidine is well-documented in the literature. It was studied by microwave experiments, ${ }^{21}$ by electron diffraction, ${ }^{26}$ and by infrared spectroscopy. ${ }^{23}$ From these works, it was concluded that the most stable conformer is the $\mathrm{NH}$ equatorial while the $\mathrm{NH}$ axial is less stable by $\sim 3 \mathrm{~kJ} \cdot \mathrm{mol}^{-1} \cdot{ }^{21,23}$ Further, these different studies point to the presence of only equatorial $\mathrm{NH}$ piperidine in the crystalline state, while in the vapor phase the equatorial $\mathrm{NH}$ conformation is predominant but in coexistence with minor amounts of the axial $\mathrm{NH}$ piperidine conformer. This larger stability of the equatorial NH conformer is also predicted by theoretical calculations. The computed energetic difference between the two conformers is close to the available experimental results. ${ }^{27}$ Selected geometrical parameters from MP2, BP86, and B3LYP full optimization with the 6-31G(d) basis set, without symmetry constrains, of piperidine are reported and compared with results available in the literature in Table 3 . The full sets of optimized coordinates for all compounds studied here are given as Supporting Information (Tables S7-S10). The computed geometrical parameters coming from the three different approaches considered are in excellent agreement with experimental results obtained for the equatorial NH conformer. This was expected since the adequacy of these methods to yield reliable geometrical data for similar but aromatic compounds had already been found. ${ }^{28-30}$

(26) Gundersen, G.; Rankin, D. W. H. Acta Chem. Scand., Ser. A 1983 37, 865 .

(27) Peeters, A.; vanAlsenoy, C.; Lenstra, A. T. H.; Geise, H. J. J. Mol. Struct.: THEOCHEM 1991, 231, 137.

(28) Ribeiro da Silva, M. A. V.; Morais, V. M. F.; Matos, M. A. R.; Rio, C. M. A. J. Org. Chem. 1995, 60, 5291.

(29) Ribeiro da Silva, M. A. V.; Matos, M. A. R.; Rio, C. M. A.; Miranda, M. S.; Morais, V. M. F. J. Phys. Chem. A 2000, 104, 6644.
The geometry of the axial conformer is not given since it is less stable than the equatorial conformer. The enthalpic difference between these two conformations is $2.3 \mathrm{~kJ} \cdot \mathrm{mol}^{-1}$ when calculated at the MP2/6-31G(d) level of theory or $3.1 \mathrm{~kJ} \cdot \mathrm{mol}^{-1}$ when the G3MP2B3 approach is used. The same is applied for the boat and twisted conformers, which are even more destabilized when compared with the $\mathrm{NH}$ equatorial and chair conformer (or $\mathrm{NCH}_{3}$ in the case of methyl derivates with $\mathrm{CH}_{3}$ attached to $\mathrm{N}$; see below). All compounds are more stable if the $\mathrm{N}-\mathrm{R}$ group, $\mathrm{R}=\mathrm{H}$ or $\mathrm{CH}_{3}$, is placed in an equatorial position and in chair conformation, in agreement with recent work. ${ }^{31}$ For example, the computed enthalpic difference between equatorial and axial conformations of 1-methylpiperidine is much larger than the value reported for piperidine. The MP2/ $6-31 \mathrm{G}(\mathrm{d})$ computed difference is $14.2 \mathrm{~kJ} \cdot \mathrm{mol}^{-1}$. Differences between computed geometrical parameters in piperidine and 1-methylpiperidine compounds are negligible, suggesting that the space occupied by the methyl group is smaller than that occupied by the nitrogen lone pair. Thus, similar conformers are predicted for piperidine and methylpiperidine.

Calculated Enthalpy of Formation for Piperidine. Two different procedures were employed to estimate the enthalpies of formation of the piperidine and their methyl derivatives. In one of these procedures, a pertinent reaction was chosen considering that the experimental enthalpies of formation of all reactants and products, with the exception of the piperidine or methylpiperidines, are known and their values are considered accurate. For the monomethylpiperidines, two different reactions were used: eq 1 in the case of 1-methylpiperidine, and eq 2 in the case of 2-, 3-, and 4-methylpiperidines.

1-methylpiperidine $(\mathrm{g})+\mathrm{NH}_{3}(\mathrm{~g}) \rightarrow$ piperidine $(\mathrm{g})+$

$$
\mathrm{CH}_{3} \mathrm{NH}_{2}(\mathrm{~g})
$$

2- or 3- or 4-methylpiperidine $(\mathrm{g})+\mathrm{CH}_{4}(\mathrm{~g}) \rightarrow$

$$
\text { piperidine }(\mathrm{g})+\mathrm{CH}_{3} \mathrm{CH}_{3}(\mathrm{~g})
$$

Two other equations were used to estimate the enthalpy of formation of piperidine:

$$
\begin{aligned}
& \text { piperidine }(\mathrm{g})+5 \mathrm{CH}_{4}(\mathrm{~g}) \rightarrow \underset{3}{\mathrm{CH}_{3} \mathrm{~N}(\mathrm{H}) \mathrm{CH}_{3}(\mathrm{~g})+} \\
& \qquad 4 \mathrm{CH}_{3} \mathrm{CH}_{3}(\mathrm{~g})
\end{aligned}
$$

piperidine $(\mathrm{g})+\mathrm{CH}_{3} \mathrm{CH}_{2} \mathrm{CH}_{3}(\mathrm{~g}) \rightarrow$ cyclohexane $(\mathrm{g})+$

$$
\mathrm{CH}_{3} \mathrm{~N}(\mathrm{H}) \mathrm{CH}_{3}
$$

The calculated enthalpies of eqs 1-4 have been combined with the experimental standard gas-phase enthalpies of formation of the species considered in these reactions: piperidine, $\Delta_{\mathrm{f}}$ $H_{\mathrm{m}}^{\mathrm{o}}(\mathrm{g})=-(47.15 \pm 0.63) \mathrm{kJ} \cdot \mathrm{mol}^{-1.5}$ ammonia, $\Delta_{\mathrm{f}} H_{\mathrm{m}}^{\mathrm{o}}(\mathrm{g})=$ $-(45.94 \pm 0.35) \mathrm{kJ} \cdot \mathrm{mol}^{-1.32}$ methylamine, $\Delta_{\mathrm{f}} H_{\mathrm{m}}^{\mathrm{o}}(\mathrm{g})=-(23.4$ $\pm 1.0) \mathrm{kJ} \cdot \mathrm{mol}^{-1,33}$ methane, $\Delta_{\mathrm{f}} H_{\mathrm{m}}^{\mathrm{o}}(\mathrm{g})=-(74.4 \pm 0.4)$ $\mathrm{kJ} \cdot \mathrm{mol}^{-1.33}$ ethane, $\Delta_{\mathrm{f}} H_{\mathrm{m}}^{\mathrm{o}}(\mathrm{g})=-(83.8 \pm 0.3) \mathrm{kJ} \cdot \mathrm{mol}^{-1.33}$ dimethylamine, $\Delta_{\mathrm{f}} H_{\mathrm{m}}^{\mathrm{o}}(\mathrm{g})=-(18.8 \pm 1.5) \mathrm{kJ} \cdot \mathrm{mol}^{-1,33}$ pro-

(30) Ribeiro da Silva, M. A. V.; Matos, M. A. R.; Rio, C. M. A.; Morais, V. M. F.; Wang, J.; Nichols, G.; Chickos, J. S. J. Phys. Chem. A 1998 104, 1774.

(31) Alkorta, I.; Elguero, J. Magn. Res. Chem. 2004, 42, 955.

(32) Cox, J. D.; Wagman, D. D.; Medvedev, V. A. CODATA Key Values for Thermodynamics; Hemisphere Publishing Corp.: New York, 1984.

(33) Pedley, J. B. Thermochemical Data and Structures of Organic Compounds; TRC Data Series: College Station, TX 1994; Vol. 1. 
TABLE 2. Derived Standard $\left(p^{\circ}=0.1\right.$ MPa) Molar Energies of Combustion, $\Delta_{\mathrm{c}} U_{\mathrm{m}}^{\mathrm{o}}$, Standard Molar Enthalpies of Combustion, $\Delta_{\mathrm{c}} H_{\mathrm{m}}^{0}$, Standard Molar Enthalpies of Formation for the Compounds in the Liquid and Gaseous Phase, $\Delta_{\mathrm{f}} H_{\mathrm{m}}^{\circ}(\mathrm{l}$ or g), and Standard Molar Enthalpies of Vaporization, $\Delta_{1}^{g} H_{\mathrm{m}}^{\mathbf{0}}$

\begin{tabular}{|c|c|c|c|c|c|}
\hline compound & $-\Delta_{\mathrm{c}} U_{\mathrm{m}}^{\mathrm{o}}(1)^{a}$ & $-\Delta_{\mathrm{c}} H_{\mathrm{m}}^{\mathrm{o}}(\mathrm{l})$ & $-\Delta_{\mathrm{f}} H_{\mathrm{m}}^{\mathrm{o}}(1)$ & $\Delta_{1}^{g} H_{\mathrm{m}}^{\mathrm{o}}$ & $-\Delta_{\mathrm{f}} H_{\mathrm{m}}^{\mathrm{o}}(\mathrm{g})$ \\
\hline 1-methyl & $4116.2 \pm 1.4$ & $4123.0 \pm 1.4$ & $95.9 \pm 1.6$ & $36.80 \pm 0.61$ & $59.1 \pm 1.7$ \\
\hline 3-methyl & $4088.5 \pm 1.1$ & $4095.3 \pm 1.1$ & $123.6 \pm 1.4$ & $44.41 \pm 0.72$ & $79.2 \pm 1.6$ \\
\hline 4-methyl & $4088.6 \pm 1.2$ & $4095.4 \pm 1.2$ & $123.5 \pm 1.5$ & $40.56 \pm 0.89$ & $82.9 \pm 1.7$ \\
\hline 2,6-dimethyl & $4736.6 \pm 1.9$ & $4744.7 \pm 1.9$ & $153.6 \pm 2.1$ & $42.38 \pm 0.68$ & $111.2 \pm 2.2$ \\
\hline 3,5-dimethyl & $4735.2 \pm 1.4$ & $4743.3 \pm 1.4$ & $155.0 \pm 1.7$ & $49.11 \pm 0.60$ & $105.9 \pm 1.8$ \\
\hline
\end{tabular}

TABLE 3. Selected Geometrical Parameters Obtained by a Full Optimization of Piperidine at Three Different Levels of Theory and Employing the 6-31G(d) Basis Set ${ }^{a}$

\begin{tabular}{|c|c|c|c|c|c|c|}
\hline & \multicolumn{4}{|c|}{ calculated (this work) } & \multicolumn{2}{|c|}{ experimental } \\
\hline & MP2 & BP86 & SVWN & B3LYP & microwave $^{b}$ & electron diffraction ${ }^{c}$ \\
\hline $\operatorname{dist}(\mathrm{N}-\mathrm{H})$ & 1.020 & 1.027 & 1.025 & 1.018 & 1.022 & 1.015 \\
\hline $\operatorname{dist}(\mathrm{N}-\mathrm{C})$ & 1.464 & 1.471 & 1.443 & 1.465 & 1.466 & 1.471 \\
\hline $\operatorname{dist}(\mathrm{C}-\mathrm{C})$ & $1.525 ; 1.529$ & $1.538 ; 1.541$ & $1.514 ; 1.517$ & $1.533 ; 1.537$ & 1.535 & 1.532 \\
\hline $\operatorname{ang}(\mathrm{H}-\mathrm{N}-\mathrm{C})$ & 109.3 & 109.2 & 110.5 & 109.7 & 104.8 & 108.5 \\
\hline $\operatorname{ang}(\mathrm{C}-\mathrm{N}-\mathrm{C})$ & 111.1 & 111.4 & 111.6 & 112.1 & 111.7 & 111.1 \\
\hline $\operatorname{ang}(\mathrm{N}-\mathrm{C}-\mathrm{C})$ & 109.1 & 109.5 & 109.6 & 109.6 & 108.0 & 109.8 \\
\hline $\operatorname{ang}\left(\mathrm{C}-\mathrm{C}_{3}-\mathrm{C}\right)$ & 110.3 & 110.5 & 110.1 & 110.7 & 110.9 & 109.9 \\
\hline $\operatorname{ang}\left(\mathrm{C}-\mathrm{C}_{4}-\mathrm{C}\right)$ & 110.6 & 110.7 & 110.4 & 110.8 & 109.9 & 111.6 \\
\hline $\operatorname{ang}(\mathrm{N}-\mathrm{C}-\mathrm{C}-\mathrm{C})$ & 57.8 & 57.1 & 57.4 & 56.6 & - & 56.9 \\
\hline $\operatorname{ang}(\mathrm{C}-\mathrm{C}-\mathrm{C}-\mathrm{C})$ & 53.4 & 52.6 & 53.8 & 52.6 & - & 53.1 \\
\hline $\operatorname{ang}(\mathrm{C}-\mathrm{N}-\mathrm{C}-\mathrm{C})$ & 63.8 & 62.9 & 62.7 & 62.2 & - & 62.7 \\
\hline
\end{tabular}

pane, $\Delta_{\mathrm{f}} H_{\mathrm{m}}^{\mathrm{o}}(\mathrm{g})=-(104.7 \pm 0.5) \mathrm{kJ} \cdot \mathrm{mol}^{-1}$; and cyclohexane, $\Delta_{\mathrm{f}} H_{\mathrm{m}}^{\mathrm{o}}(\mathrm{g})=-(123.3 \pm 0.8) \mathrm{kJ} \cdot \mathrm{mol}^{-1}, 33$ allowing the estimation of the enthalpies of formation of 1-methylpiperidine, 2-methylpiperidine, 3-methylpiperidine, 4-methylpiperidine, and piperidine.

In the other procedure, the enthalpy of formation of the compound is estimated from the G3MP2B3 computed enthalpy of atomization using the enthalpy of formation of the elements, hydrogen, carbon, and nitrogen. This procedure is commonly applied to derive enthalpies of formation from theoretical computations, using one of the Gaussian-N theories. Generally, atomization reactions are not combined with other theoretical approaches due to the inaccuracy of the corresponding computed atomization energies. This lack of accuracy makes it unable for us to calculate reliable enthalpies of formation, even if the compounds studied are molecularly simple and small. For example, the average absolute deviation of the enthalpies of formation of the G2 set computed with the BP86 functional is about $85 \mathrm{~kJ} \cdot \mathrm{mol}^{-1}$. $^{34}$ When combined with an isodesmic reaction, this BP86 functional was found to yield excellent enthalpies of formation for phenol and dichlorophenols ${ }^{35}$ and also for chloronitroanilines. ${ }^{36}$ In these two works, the BP86 computational approach was found to be even better than the B3LYP hybrid method, which was parametrized to reproduce available experimental thermochemical data, with a mean deviation from experimental results of about $10 \mathrm{~kJ} \cdot \mathrm{mol}^{-1}$.

Previously, Vayner and Ball ${ }^{20}$ reported that the HF, BLYP, and B3LYP methods gave poor results when applied to the

(34) Curtiss, L. A.; Redfern, P. C.; Raghavachari, K.; Pople, J. A. J. Chem. Phys. 1998, 109, 42.

(35) Gomes, J. R. B.; Ribeiro da Silva, M. A. V. J. Phys. Chem. A 2003, $107,869$.

(36) Ribeiro da Silva, M. A. V.; Lima, L. M. S. S.; Amaral, L. M. P. F.; Ferreira, A. I. M. C. L.; Gomes, J. R. B. J. Chem. Thermodyn. 2003, 35, 1343.
TABLE 4. Estimated Enthalpy of Formation for Piperidine, at $T$ $=298.15 \mathrm{~K}$, by Different Theoretical Approaches Using the 6-31G* Basis Set for Both Optimization and Calculation of Frequencies ${ }^{a}$

\begin{tabular}{ccccccccc}
\hline reaction & HF & MP2 & BP86 & PBE & PW91 & SVWN & B3LYP & G3MP2B3 \\
\hline $3^{b}$ & -24.1 & -54.2 & -31.7 & -30.5 & -29.0 & -39.9 & -26.9 & -50.8 \\
$4^{b}$ & -52.5 & -52.5 & -51.4 & -51.5 & -51.2 & -51.8 & -51.6 & -51.8 \\
$5^{c}$ & -15.1 & -52.2 & - & - & - & -39.7 & -19.9 & -
\end{tabular}

${ }^{a}$ Experimental results for piperidine are $-(47.15 \pm 0.63)$ and $-(48.6$ $\pm 2.6) \mathrm{kJ} \cdot \mathrm{mol}^{-1}$, taken from refs 5 and 6 , respectively. ${ }^{b}$ This work. ${ }^{c}$ Estimated values taken from ref 20.

estimation of the gas-phase enthalpy of formation of piperidine, but the SVWN and MP2 methods were found to give better results. In the present work, we used these four methods and eqs 3 and 4 to estimate the enthalpies of formation of piperidine. As explained above, the BP86 exchange-correlation functional seems to be a good choice for this kind of study and was also used in the present work, as well as the PBE and PW91 functionals, for comparison purposes. The computed enthalpies of formation are compared in Table 4 with experimental data and with the computed values of Vayner and Ball, who used a different, but similar, reaction scheme shown below.

$$
\begin{array}{r}
\text { piperidine }(\mathrm{g})+\mathrm{NH}_{3}(\mathrm{~g})+5 \mathrm{CH}_{4}(\mathrm{~g}) \rightarrow 2 \underset{3}{2 \mathrm{CH}_{3} \mathrm{NH}_{2}(\mathrm{~g})+} \\
4 \mathrm{C}_{2} \mathrm{H}_{6}(\mathrm{~g})(5)
\end{array}
$$

The analysis of results given in Table 4 shows that only the MP2 and G3MP2B3 approaches yield consistent results that do not depend on the working reaction used for the estimation. All DFT methods and the Hartree-Fock approach give erroneous values if eq 3 or 5 is used. Interestingly enough, all the methods yield practically the same result if eq 4 is used, which gives the idea that in all DFT methods and also in HartreeFock the errors noticed by Vayner and Ball are canceled by the use of a similar species, cyclohexane, as one of the products in 
eq 4. This suggests that only this reaction is truly isodesmic, while eq 3 is less isodesmic. The poor performance of the DFT methods is not due to any problem in the optimization procedure since, as shown in Table 3, MP2 and DFT optimized structures for piperidine are almost the same. Further, the G3MP2B3 method uses the B3LYP/6-31G(d) approach, for both geometry optimization and calculations of frequencies, and the G3MP2B3 estimated values are in good agreement with available experimental data. These problems seem to be due to dispersion interactions, also denoted by van der Waals interactions, between the $-\mathrm{CH}_{2}-$ groups in positions 1,3 , and 5 or between positions 2,4 , and 6 , in the case of cyclohexane. In a similar fashion, these interactions are also present in the piperidine ring. Dispersion interactions are known to be badly described by current DFT methods, but the MP2 approach is well-suitable to deal with these kinds of interactions. ${ }^{37}$ Therefore, the DFT methods must be used with caution when dealing with molecules whose internal geometry is capable of producing these kinds of internal interactions. This leads us to conclude that a previous check of the computational approach is needed before entailing the theoretical estimation of thermodynamic quantities. The only DFT method whose results are not too far from the experimental gas-phase standard enthalpy of formation of piperidine, when eq 3 or 5 is used, is the SVWN functional. Nevertheless, the differences are about $10 \mathrm{~kJ} \cdot \mathrm{mol}^{-1}$.

The enthalpy of formation of piperidine was also estimated from the enthalpy of the reaction of atomization computed at the G3MP2B3 level of theory and the experimental gas-phase enthalpies of formation of hydrogen, $\Delta_{\mathrm{f}} H_{\mathrm{m}}^{\mathrm{o}}(\mathrm{g})=218.00 \mathrm{~kJ} \cdot$ $\mathrm{mol}^{-1}$, carbon, $\Delta_{\mathrm{f}} H_{\mathrm{m}}^{\mathrm{o}}(\mathrm{g})=716.67 \mathrm{~kJ} \cdot \mathrm{mol}^{-1}$, and nitrogen, $\Delta_{\mathrm{f}}$ $H_{\mathrm{m}}^{\mathrm{o}}(\mathrm{g})=472.68 \mathrm{~kJ} \cdot \mathrm{mol}^{-1}$ atoms. ${ }^{38}$ The estimated value is $\Delta_{\mathrm{f}}$ $H_{\mathrm{m}}^{\mathrm{o}}(\mathrm{g})=-48.2 \mathrm{~kJ} \cdot \mathrm{mol}^{-1}$ between the two experimental values available in the literature.

The Effect of Augmented Basis Sets on B3LYP Computed Enthalpies of Formation. The influence of the size of the basis set considered in B3LYP calculations was analyzed in the case of piperidine and 2-methylpiperidine using, respectively, eqs 3 and 2. The effect of augmentation of the standard 6-31G(d) basis set with more diffuse and polarization functions on calculated enthalpies of formation for these two species is depicted in Figure 1.

The improvement of the estimated enthalpy of formation with the use of larger basis sets is more evident for the nonsubstituted derivative but, even in the most interesting situation, the difference between estimated and experimental values is larger than $10 \mathrm{~kJ} \cdot \mathrm{mol}^{-1}$; the computed B3LYP/6-311G(d,p) enthalpy of formation is $-31.2 \mathrm{~kJ} \cdot \mathrm{mol}^{-1}$. It is found also that the use of diffuse functions produce even worse calculated enthalpies of formation, which supports the conclusion that the DFT problems are caused by the bad description of dispersion forces since larger electronic clouds will, in principle, enhance these problems. It is found for 2-methylpiperidine that the inclusion of additional polarization and diffuse functions almost do not change the value of the estimated enthalpy. The difference between the $6-31 \mathrm{G}(\mathrm{d})$ and the $6-31 \mathrm{G}(2 \mathrm{~d}, 2 \mathrm{p})$ calculated values is only $0.8 \mathrm{~kJ} \cdot \mathrm{mol}^{-1}$. Interestingly, the smaller basis set dependence reported for 2-methylpiperidine suggests that eq 2 is truly isodesmic, but as it will be shown in the next section, B3LYP values are still far from experimental ones.

(37) Zhechkov, L.; Heine, T.; Patchkovskii, S.; Seifert, G.; Duarte, H. A. J. Chem. Theory Comput. 2005, 1, 841.

(38) Chase, M. W., Jr. J. Phys. Chem. Ref. Data 1998, 1, Monograph 9.

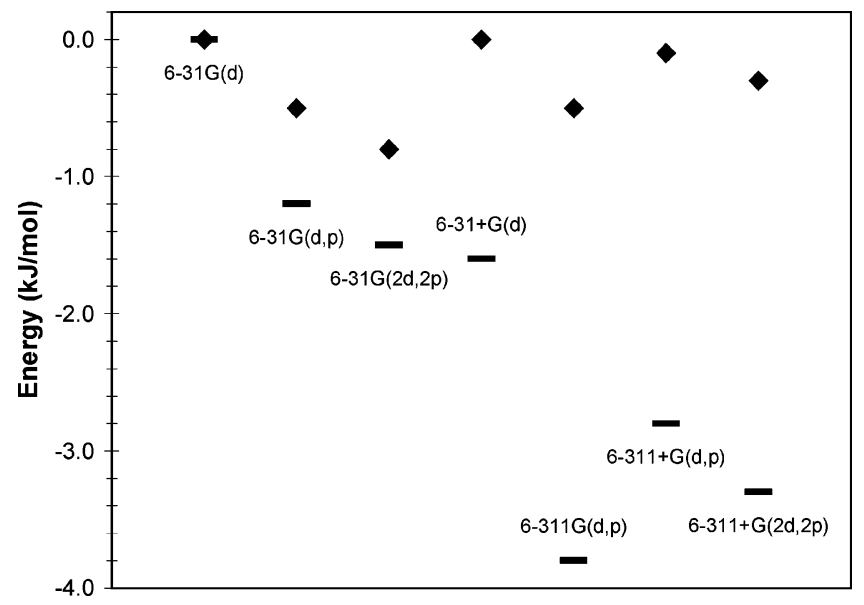

FIGURE 1. Effect of the basis set on the B3LYP computed enthalpy of formation of piperidine (-) and 2-methylpiperidine ( ).

TABLE 5. Computed Enthalpies of Formation, $T=298.15 \mathrm{~K}$, of the Four Methylpiperidine Isomers ${ }^{a}$

\begin{tabular}{|c|c|c|c|c|c|c|}
\hline & $\mathrm{B}^{3} \mathrm{LYP}^{b}$ & $\mathrm{SVWN}^{b}$ & $\mathrm{MP} 2^{b}$ & $\mathrm{G} 3 \mathrm{MP} 2 \mathrm{~B} 3^{b}$ & $\mathrm{G}_{3} \mathrm{MP}_{2} \mathrm{~B} 3^{c}$ & experimental \\
\hline 1-methyl & -45.6 & -59.1 & -59.8 & -61.0 & -59.7 & $\begin{aligned}-59.1 & \pm 1.7^{d} \\
-61.39 & \pm 0.88^{e}\end{aligned}$ \\
\hline -methyl & -74.7 & -85.6 & -85.9 & -85.8 & -86.4 & $-84.5 \pm 1.1^{f}$ \\
\hline 3-methyl & -68.2 & -78.9 & -78.6 & -79.0 & -79.6 & $-79.5 \pm 2.9^{d}$ \\
\hline 4-methyl & -68.5 & -79.0 & -79.1 & -79.4 & -80.0 & $-82.7 \pm 3.2^{d}$ \\
\hline
\end{tabular}

${ }^{a}$ Values in $\mathrm{kJ} \cdot \mathrm{mol}^{-1} \cdot{ }^{b}$ Calculated from reaction 1 or $2 .{ }^{c}$ Calculated from atomization reaction. ${ }^{d}$ This work. ${ }^{e}$ Reference $10 .{ }^{f}$ Reference 5 .

Calculated Enthalpies of Formation for Methylpiperidines. The estimated values for the four methylpiperidines are reported in Table 5. Again, the B3LYP method, which is known to provide accurate thermochemical data for a large number of compounds, ${ }^{28-30,35,36}$ fails to predict the enthalpies of formation of the methylpiperidines, even with the use of a similar species, piperidine, as one of the products of eqs 1 and 2. Estimated values are systematically more positive than the experimental results by $10-14 \mathrm{~kJ} \cdot \mathrm{mol}^{-1}$. It is noteworthy that the SVWN estimated values are in excellent agreement with experimental results. Similar to that found for piperidine, the MP2 and G3MP2B3 approaches still give excellent results. The use of the G3MP2B3 approach together with the use of the reaction of atomization gives slightly better results than with the use of eq 1 or 2 . The best comparison between estimated and experimental values is obtained for the G3MP2B3/atomization reaction approach, with a mean deviation of only $1.1 \mathrm{~kJ} \cdot \mathrm{mol}^{-1}$. Therefore, this strategy was employed in the estimation of the gas-phase standard molar enthalpies of formation of the 12 dimethylpiperidine isomers. The values given in Table 5 show that the 2-methylpiperidine isomer is the most stable and, as expected, the 1-methylpiperidine is the least stable. In the latter case, this may be explained by a balance of chemical bonds, which are less stable in the case of 1-methylpiperidine (one $\mathrm{C}-\mathrm{N}$ and one $\mathrm{C}-\mathrm{H}$ bonds) than in the other three methyl isomers (one $\mathrm{C}-\mathrm{C}$ and one $\mathrm{N}-\mathrm{H}$ bonds). The 2-methyl derivative is somewhat more stable than the 3-methyl and 4-methylpiperidine derivatives. In the case of the 2-methyl isomer, the smaller distance between the methyl group and the nitrogen atom, and consequently of its lone pair, enables some stabilization of this molecule due to inductive effects (Figure $2)$.

Calculated Enthalpies of Formation for Dimethylpiperidines. Table 6 includes the experimental standard molar 


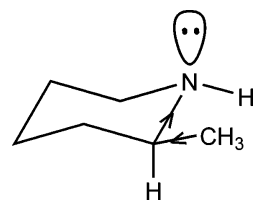

FIGURE 2. Sources of stabilization in 2-methylpiperidine.

TABLE 6. Enthalpies of formation, $T=298.15 \mathrm{~K}$, of the 12 Dimethylpiperidine Isomers $^{a}$

\begin{tabular}{cll}
\hline & G3MP2B3 & experimental \\
\hline 1,2-dimethyl & -76.3 (cis) & - \\
& -85.3 (trans) & - \\
1,3-dimethyl & -86.9 (cis) & - \\
& -81.7 (trans) & - \\
1,4-dimethyl & -79.3 (cis) & - \\
& -87.3 (trans) & - \\
2,2-dimethyl & -111.7 & - \\
2,3-dimethyl & -105.0 (cis) & - \\
& -110.4 (trans) & - \\
2,4-dimethyl & -113.9 (cis) & $-111.2 \pm 2.2$ \\
& -105.5 (trans) & - \\
2,5-dimethyl & -108.2 (cis) & - \\
& -113.6 (trans) & $-105.9 \pm 1.8$ \\
2,6-dimethyl & -120.3 (cis) \\
& -108.2 (trans) & - \\
3,3-dimethyl & -107.6 & - \\
3,4-dimethyl & -98.4 (cis) & -103.7 (trans) \\
3,5-dimethyl & -106.6 (cis) & -101.4 (trans) \\
& -104.9 & \\
4,4-dimethyl & cis &
\end{tabular}

enthalpies of formation of 2,6- and 3,5-dimethylpiperidines and compares these values with those obtained by the use of the G3MP2B3 approach and the reaction of atomization.

The comparison between computed and experimental data shows that the results for 3,5-dimethylpiperidine are in excellent agreement, while a significant difference is found for 2,6dimethylpiperidine. The fact that the G3MP2B3 approach was capable to yield excellent estimates for piperidine, all methylpiperidines, and 3,5-dimethylpiperidine led us to suspect that the 2,6-dimethylpiperidine sample used in the experimental work contained some sort of contamination, even though it was repeatedly distilled prior to usage and no impurities were detected by GLC (see Materials section). Electrospray ionization mass spectrometry (ESI-MS) of a freshly distilled sample allowed us to confirm compound integrity, as a single peak at $\mathrm{m} / z 114.2\left(\mathrm{MH}^{+}\right)$was detected. The ESI-MS technique did not allow for detection below $\mathrm{m} / \mathrm{z} 50$, and thus, the presence of low molecular weight contaminants, such as water, could not be ruled out from this analysis. Another possible explanation for the slight discrepancy observed between the computational and experimental data for this compound could be that the sample used was a mixture of cis and trans isomers, despite the supplier's information regarding this compound as being the pure cis isomer (Aldrich ref D180300). Hence, we have further analyzed the distilled compound by ${ }^{1} \mathrm{H}$ - and ${ }^{13} \mathrm{C}$ NMR, which enabled us to confirm its purity and structure, as no peaks other than those of cis-2,6-dimethylpiperidine could be observed (detailed spectral data supplied in Supporting Information). A similar sample characterization was done with 3,5-dimethylpiperidine, purchased as a mixture of cis/trans isomers (Aldrich ref 186104), and in this case, ${ }^{1} \mathrm{H}$ NMR analysis allowed us to realize that the compound was $28.6 \%$ in trans and $71.4 \%$ in cis configuration (detailed spectral data in Supporting Information). Considering the cis/trans composition given above for 3,5dimethylpiperidine and the $\Delta_{\mathrm{f}} H_{\mathrm{m}}^{\mathrm{o}}(\mathrm{g})$ computed values included in Table 6 for these two configurations, the computed enthalpy of formation for 3,5-dimethylpiperidine that must be compared with the experimental result is $\Delta_{\mathrm{f}} H_{\mathrm{m}}^{\mathrm{o}}(\mathrm{g})=-105.0 \mathrm{~kJ} \cdot \mathrm{mol}^{-1}$.

The analysis of the computed values shows again that substitution at the nitrogen atom is less stable than when occurring at the carbon atoms of the piperidine ring. For the $1, X$-dimethyl derivatives, the position of the second methyl at the nitrogen's adjacent carbon atom is the most unstable situation due to steric effects between the methyl groups. For the other dimethylpiperidines, substitutions at positions 2 or 4 (rather than at positions 1 and 3) are the ones that stabilize more efficiently the entire molecule, especially in the case of the 2,6-dimethyl isomer (6-substitution equivalent to 2 -substitution in the nonsubstituted piperidine ring). Further, insertion of two methyl groups at the same carbon atom does not introduce any significant destabilization, which is easily understood if one compares the enthalpies of formation of 2,4-dimethylpiperidine with those of 2,2-dimethyl and 4,4-dimethylpiperidines.

Enthalpic Increments and Correlations. The analysis of the enthalpic increments of the experimental enthalpies of formation on going from piperidine to methylpiperidines and to dimethylpiperidines is illustrated in Figure 3. This graphical representation clearly shows that substitution at position 1 is unfavorable when compared with positions 2,3 , and 4 . The enthalpic increment when substitution occurs at the nitrogen atom is less than one-half of the increments found for substitution at the carbon atoms. Interestingly enough, the insertion of a second methyl group on an analogous position in 2-methylpiperidine or in 3-methylpiperidine, yielding 2,6-dimethylpiperidine or 3,5-dimethylpiperidine, respectively, leads to the same calculated enthalpic increment $\left(-26.7 \mathrm{~kJ} \cdot \mathrm{mol}^{-1}\right)$ if the experimental enthalpy of formation for 2,6-dimethylpiperidine is considered. Also interesting is the fact that the inclusion of two other methyl groups in positions 2 and 6 of 2,6-dimethylpiperidine, yielding 2,2,6,6-tetramethylpiperidine, yields practically the same enthalpic contribution per methyl group inserted (Figure 4). The insertion of a second methyl group in 2-methyl or 3-methylpiperidine lowers the enthalpy by $\sim 27 \mathrm{~kJ} \cdot \mathrm{mol}^{-1}$, which is identical to the enthalpic increment found for 2,2,6,6tetramethylpiperidine, $\sim 26 \mathrm{~kJ} \cdot \mathrm{mol}^{-1}$. These results suggest that insertion of a second methyl group produces equal stabilization whichever position is occupied. This picture contradicts some of the considerations given in preceding subsections. Further, the stabilization of similar magnitude observed for the insertion of a second methyl group at the same carbon atom, as it happens twice in 2,2,6,6-tetramethylpiperidine, seems rather unlikely. Interestingly, the G3MP2B3 computed enthalpy of formation of 2,2,6,6-tetramethylpiperidine is also more negative by $\sim 8$ $\mathrm{kJ} \cdot \mathrm{mol}^{-1}$ than the experimental value obtained by another researcher, ${ }^{19}$ giving support to the experimental value of this work for 2,6-dimethylpiperidine.

If the theoretically estimated enthalpy of formation for 2,6dimethylpiperidine is considered, the calculated increment on going from 2-dimethylpiperidine to 2,6-dimethylpiperidine is $-35.8 \mathrm{~kJ} \cdot \mathrm{mol}^{-1}$. This means that insertion at position 6 is more favorable than insertions at position 3 or 4 . This is in agreement with an enhanced stabilization of the molecule due to inductive effects as commented earlier, and further, it means that the introduction of two additional methyl groups when going from 


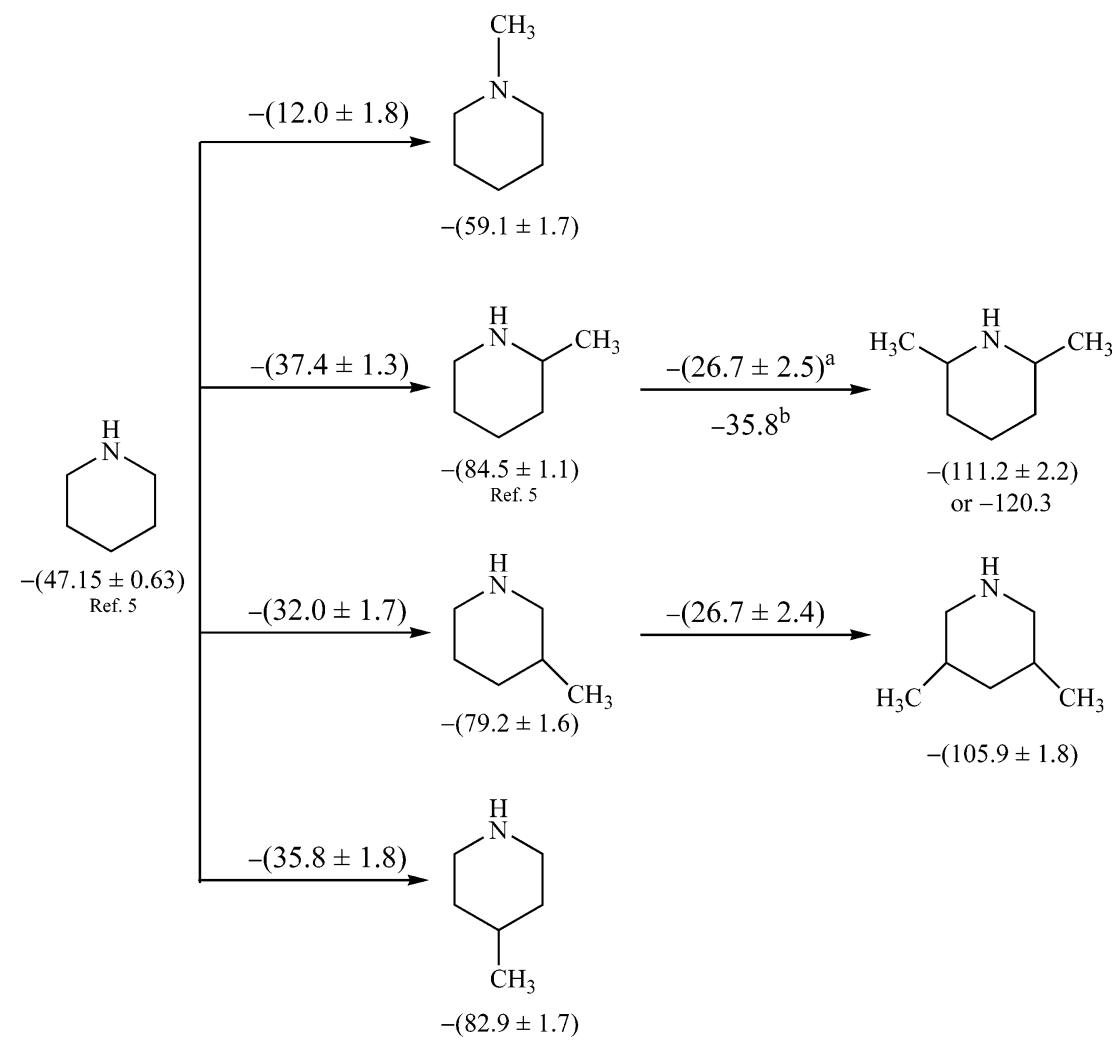

FIGURE 3. Changes in the enthalpy of piperidine due to insertion of methyl groups. Values in $\mathrm{kJ} \cdot \mathrm{mol}^{-1}$. (a) Experimental enthalpy of formation of 2,6-dimethylpiperidine is considered. (b) G3MP2B3 enthalpy of formation of 2,6-dimethylpiperidine is considered.

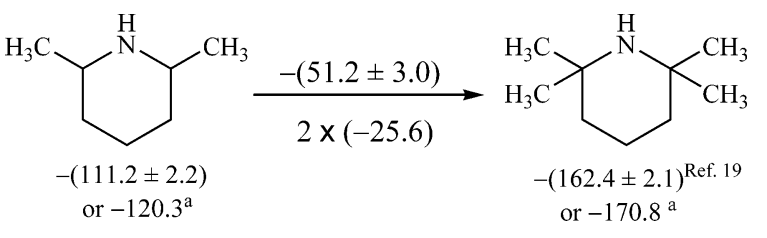

FIGURE 4. Enthalpic change caused by the insertion of two additional methyl groups in positions 2 and 6 of 2,6-dimethylpiperidine. Values in $\mathrm{kJ} \cdot \mathrm{mol}^{-1}$. (a) G3MP2B3 enthalpy of formation.

2,6-dimethylpiperidine to 2,2,6,6-tetramethylpiperidine is not as favorable as when going from piperidine to 2,6-dimethylpiperidine. If the G3MP2B3 values are used, then the increments shown in Figures 3 and 4 change to $-38.2 \mathrm{~kJ} \cdot \mathrm{mol}^{-1}$ from piperidine to 2 -methylpiperidine, $-33.9 \mathrm{~kJ} \cdot \mathrm{mol}^{-1}$ from 2 -methylpiperidine to 2,6-dimethylpiperidine, and $2 \times(-25.2)$ $\mathrm{kJ} \cdot \mathrm{mol}^{-1}$ from 2,6-dimethylpiperidine to 2,2,6,6-tetramethylpiperidine.

In Figure 5, it is shown that the insertion of one methylene group in 1-methylpiperidine, yielding 1-ethylpiperidine, is identical (within the intervals defined by their uncertainties) to the enthalpic changes on going from 1-ethylpiperidine to 1-propylpiperidine and from 1-propylpiperidine to 1-butylpiperidine. A similar variation of $-25.3 \mathrm{~kJ} \cdot \mathrm{mol}^{-1}$ was found from comparison of the enthalpy of formation of 2-methylpiperidine with that of 2-ethylpiperidine, as reported in another experimental work. ${ }^{39}$

\section{Conclusions}

A combined experimental and computational study has been carried out to manage the standard molar enthalpies of formation, in the gas phase and at $T=298.15 \mathrm{~K}$, of piperidine, all methylpiperidine, and all dimethylpiperidine compounds. From the experimental values reported in the present work, it was possible to find the relative enthalpic increments due to the introduction of either methyl groups into the piperidine ring or methylene groups into the $N$-alkyl substituent of the piperidine. The results clearly show that a methyl group attached to the nitrogen atom of piperidine is much less stabilizing than methyl substitution at the carbon atoms. On going from $N$-methylpiperidine to heavier $N$-alkylpiperidines such as 1-ethylpiperidine, 2-ethylpiperidine, 1-propylpiperidine, and 1-butylpiperidine, an enthalpic increment of about -20 to $-25 \mathrm{~kJ} \cdot \mathrm{mol}^{-1}$, per extra methylene group inserted, is observed. The effects of adding a

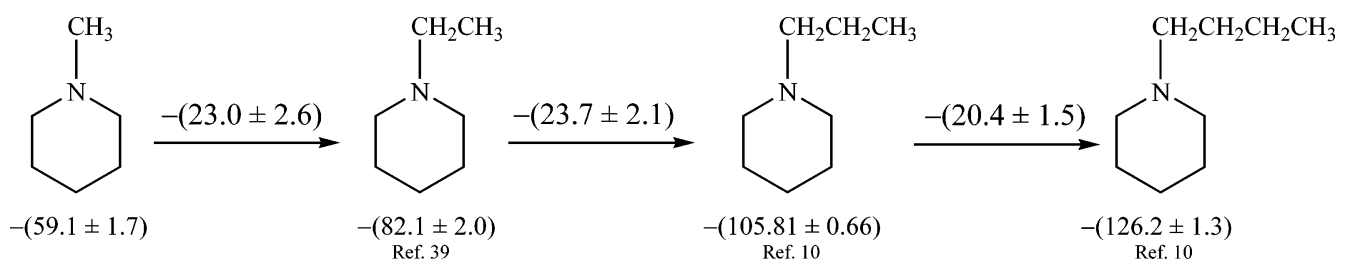

FIGURE 5. Enthalpic changes due to insertion of methylene groups into the $\mathrm{N}-\mathrm{CH}_{3}$ bond of 1-methylpiperidine, yielding heavier alkylpiperidines. Values in $\mathrm{kJ} \cdot \mathrm{mol}^{-1}$. 
second methyl group to R-methylpiperidines depend on the position of insertion.

Several computational approaches together with selected working reactions were also used in the present work. These have been used to estimate the enthalpies of formation of piperidine, the four methylpiperidine isomers, the 12 dimethylpiperidines, and the 2,2,6,6-tetramethylpiperidines. For all these cyclic amines, almost all DFT exchange correlation functionals tested fail in the estimation of gas-phase enthalpies of formation. Only the SVWN functional is capable to reproduce the thermochemistry of this class of compounds if a well-chosen working reaction is used. The MP2 and G3MP2B3 approaches were found to give consistent values, which do not largely depend on the working reaction used and that are in close agreement with experiment. The most accurate values are those coming from the G3MP2B3 calculations, while the SVWN approach seems to be the best method in terms of computational cost/accuracy relation. From the results reported in this work, it is possible to conclude that a previous check of the computational approach is required before entailing the theoretical estimation of thermodynamic quantities. This check must be done by direct comparison of theoretical and experimental results available for compounds with close structures. It is also important to consider that isodesmic reactions with similar structures in both sides of the chemical equation, such as that used to estimate the enthalpy of formation of methylpiperidines, do not guarantee well-estimated enthalpies of formation.

\section{Experimental Section}

Materials. 1-Methylpiperidine (CAS 626-67-5), purity 99\%, 3-methylpiperidine (CAS 626-56-2), purity 99\%, 4-methylpiperidine (CAS 626-58-4), purity 96\%, cis-2,6-dimethylpiperidine (CAS 50403-0), purity 98\%, and 3,5-dimethylpiperidine (CAS 35794-11-7), purity $96 \%$, all in the liquid state, were obtained commercially. The compounds were purified by repeated distillations and stored and handled under nitrogen atmosphere. The purity was checked by GLC and carbon dioxide recovery from the combustion measurements. The average ratios of the mass of carbon dioxide recovered to that calculated from the mass of samples were: 1-methylpiperidine, 0.99937; 3-methylpiperidine, 0.99973; 4-methylpiperidine, 0.100002; 2,6-dimethylpiperidine, 0.99673; and 3,5dimethylpiperidine, 0.99800 . Compounds cis-2,6-dimethylpiperidine and 3,5-dimethylpiperidine were found to be hygroscopic and absorbed a small amount of water when handled during the experiment as shown by the $\mathrm{CO}_{2}$ recoveries from the combustion and confirmed by Karl Fischer titrations. The absence of impurities other than water was checked by GLC, and compound structure was further confirmed by ESI-MS, ${ }^{1} \mathrm{H} \mathrm{NMR}\left(\mathrm{CDCl}_{3}, 300 \mathrm{MHz}\right)$, and ${ }^{13} \mathrm{C} \mathrm{NMR}\left(\mathrm{CDCl}_{3}, 75.4 \mathrm{MHz}\right)$.

Procedure for Combustion Measurements. The standard massic energies of combustion of compounds studied experimentally (i.e., 1-methylpiperidine, 3-methylpiperidine, 4-methylpiperidine, 2,6-dimethylpiperidine, and 3,5-dimethylpiperidine), all in liquid state, were measured by static bomb combustion calorimetry. The combustion bomb used was a twin-valve combustion bomb made by stainless steel and with an internal volume of $0.340 \mathrm{~cm}^{3}$. A detailed description of the apparatus and the technique may be found in the literature. ${ }^{40,41}$

(39) Ribeiro da Silva, M. A. V.; Cabral, J. I. T. A.; Gomes, J. R. B. J. Chem. Thermodyn., in press.

(40) Ribeiro da Silva, M. A. V.; Ribeiro da Silva, M. D. M. C.; Pilcher, G. Rev. Port. Quim. 1984, 26, 163 .

(41) Ribeiro da Silva, M. A. V.; Ribeiro da Silva, M. D. M. C.; Pilcher, G. J. Chem. Thermodyn. 1984, 16, 1149.
The energy equivalent of the calorimeter and the bomb was determined from the combustion of benzoic acid Thermochemical Standard.

The liquid samples were burnt in sealed polyester bags made of Melinex (0.025-mm thickness), previously weighed, with a massic energy of combustion of dry Melinex as $\Delta_{\mathrm{c}} u^{\mathrm{o}}=-(22902 \pm 5)$ $\mathrm{J} \cdot \mathrm{g}^{-1}{ }^{42}$ The mass of Melinex used in each experiment was corrected for the mass fraction of water $(w=0.0032)$, and the mass of $\mathrm{CO}_{2}$ produced from it was calculated using a factor previously reported. ${ }^{42}$

In all experiments, no carbon soot residue, resulting from incomplete combustions, was observed.

The ignition of the samples was made at $T=298.15 \mathrm{~K}$. Corrections were made for the energy of combustion of the cottonthread fuse, the Melinex, and the nitric acid formed in each experiment. The gases of combustion were analyzed to recover the carbon dioxide resulting from the combustion experiments. The amounts of the compounds burned were determined from the $\mathrm{CO}_{2}$ recoveries.

For all compounds, the correction to standard state, $\Delta U_{\Sigma}$, and the calculation of $\Delta_{\mathrm{c}} u^{0}$ were made as described by Hubbard et al. ${ }^{43}$ For each compound, $(\partial u / \partial T)_{\mathrm{T}}$ was assumed to be $-0.2 \mathrm{~J} \cdot \mathrm{g}^{-1}$, at $T$ $=298.15 \mathrm{~K}$, a typical value of organic compounds. ${ }^{44}$ The molar masses used for the elements were those recommended by the IUPAC Commission. ${ }^{45}$ Experimental details of the combustion calorimetry are presented in the Supporting Information.

Procedure for Calvet Microcalorimety Experiments. The standard molar enthalpies of vaporization of the compounds were determined by microcalorimetry, using for liquids a technique similar to that described for the sublimation of solids by Skinner et al. ${ }^{25}$ The apparatus and the technique have been described previously in the literature. ${ }^{46}$ The calibration of the calorimeter was made with $n$-undecane. Details of the technique used and the calibration procedure are given in the Supporting Information.

Samples of about $5 \mathrm{mg}$ of each compound, contained in thin glass capillary tubes sealed at one end, were dropped at room temperature into the hot zone of a high-temperature Calvet microcalorimeter, held at $T=334 \mathrm{~K}$ for the compounds $1-, 3-$, and 4-methylpiperidine, and at $T=226 \mathrm{~K}$ for the compounds 2,6and 3,5-dimethylpiperidine. The thermal corrections for the glass capillaries were made by dropping tubes of nearly equal mass, simultaneously, into each of the twin cells. After a stabilization period, the sample was removed from the hot zone by vacuum evaporation. The observed values of vaporization enthalpies, at the temperature of the experiments, were corrected to $T=298.15 \mathrm{~K}$ using $\Delta_{298 \mathrm{~K}}^{T} H_{\mathrm{m}}^{\mathrm{o}}$ (g) estimated by a group scheme based on values of Messerly et al. ${ }^{47}$ and of Stull et al., ${ }^{48}$ yielding the following corrections:

For 1-methylpiperidine, $\Delta_{298.15 \mathrm{~K}}^{334.1 \mathrm{~K}} H_{\mathrm{m}}^{\mathrm{o}}(\mathrm{g})=4.68 \mathrm{~kJ} \cdot \mathrm{mol}^{-1}$; for 3-methylpiperidine, $\Delta_{298.15 \mathrm{~K}}^{334.3 \mathrm{~K}} H_{\mathrm{m}}^{\mathrm{o}}(\mathrm{g})=5.22 \mathrm{~kJ} \cdot \mathrm{mol}^{-1}$; for 4-methylpiperidine, $\Delta_{298.15 \mathrm{~K}}^{334.4 \mathrm{~K}} H_{\mathrm{m}}^{\mathrm{o}}(\mathrm{g})=5.25 \mathrm{~kJ} \cdot \mathrm{mol}^{-1}$; and for 2,6-dimethylpiperidine and 3,5-dimethylpiperidine, $\Delta_{298.15 \mathrm{~K}}^{326.6 \mathrm{~K}} H_{\mathrm{m}}^{\mathrm{o}}(\mathrm{g})=4.77$ $\mathrm{kJ} \cdot \mathrm{mol}^{-1}$. The schemes applied for all these compounds are presented in the Supporting Information.

Theoretical Calculations. Four different theoretical approaches were used to obtain accurate energies and enthalpies, at $T=298.15$ $\mathrm{K}$, for the different compounds considered in this work. These are the Møller-Plesset perturbation theory second-order correction to

(42) Skinner, H. A.; Snelson, A. Trans. Faraday Soc. 1960, 56, 1776. (43) Hubbard, W. N.; Scott, D. W.; Waddington, G. Experimental Thermochemistry; Rossini, F. D., Ed.; Interscience: New York, 1956; Vol. 1, Chapter 5.

(44) Washburn, E. N. J. Res. Natl. Bur. Stand. (U.S.) 1933, 10, 525.

(45) Loss, R. D. Pure Appl. Chem. 2003, 35, 1107.

(46) Santos, L. M. N. B. F.; Schröder, B.; Fernandes, O. O. P.; Ribeiro da Silva, M. A. V. Thermochim. Acta 2004, 415, 15.

(47) Messerly, J. F.; Todd, S. S.; Finke, H. L.; Good, W. D.; Gommon, B. E. J. Chem. Thermodyn. 1988, 20, 209.

(48) Stull, D. R.; Westrum, E. F.; Sinke, G. C. The Chemical Thermodynamics of Organic Compounds; Wiley: New York, 1969. 
the Hartree-Fock energy (MP2); ${ }^{49}$ the density functional theory (DFT)-based methods: the SVWN-LSDA method, ${ }^{50,51}$ the BP86 pure GGA method, ${ }^{52,53}$ the PW91PW91 pure GGA method, ${ }^{54}$ and the B3LYP hybrid method; ${ }^{55,56}$ and the G3MP2B3 approach based on the Gaussian-3 theory (G3). ${ }^{57}$ The MP2 calculations were carried out by inclusion of all electrons and considering the standard 6-31G(d) basis set. The final energies were corrected for $T=298.15 \mathrm{~K}$ by the calculation of vibrational frequencies at the same level of theory and including a scale factor of $0.9661 .{ }^{58}$ In DFT calculations, a similar strategy was followed but considered different scaling factors in the calculation of frequencies. For the BP86/6-31G(d) calculations, a scale factor of 1.0108 was used, and in B3LYP/ 6-31G(d) calculations, a different scale factor of 0.9804 was used as suggested by Scott and Radom. ${ }^{58}$ No scale factor was used in the SVWN and PW91 calculation of frequencies. In some test cases, the influence of added diffuse and polarization functions in the final computed gas-phase enthalpies of formation was analyzed. In the G3-based calculations, the standard G3MP2B3 approach was used as included in the Gaussian 98 package. ${ }^{59}$ In this modification of the original G3 approach, the main differences are in the calculation of harmonic frequencies, which is now performed at the B3LYP/

(49) Møller, C.; Plesset, M. S. Phys. Rev. 1934, 46, 618.

(50) Slater, J. C. Quantum Theory of Molecules and Solids: Vol. 4, The Self-Consistent Field for Molecular and Solids; McGraw-Hill: New York, 1974.

(51) Vosko, S. H.; Wilk, L.; Nusair, M. Can. J. Phys. 1980, 58, 1200.

(52) Becke, A. D. Phys. Rev. A 1988, 38, 3098.

(53) Perdew, J. P. Phys. Rev. B 1986, 33, 8822

(54) Perdew, J. P. In Electronic Structure of Solids; Ziesche, P., Eschrig,

H., Eds.; Akademie Verlag: Berlin, 1991; p 11.

(55) Becke, A. D. J. Chem. Phys. 1993, 98, 5648.

(56) Lee, C.; Yang, W.; Parr, R. G. Phys. Rev. B 1980, 37, 785.

(57) Curtiss, L. A.; Raghavachari, K.; Redfern, P. C.; Rassolov, V.; Pople, J. A. J. Chem. Phys. 1998, 109, 7764.

(58) Scott, A. P.; Radom, L. J. Phys. Chem. 1996, 100, 16502.
6-31G(d) level and the fourth-order Møller-Plesset perturbation theory (MP4) is substituted by the computational less-demanding MP2 approach.

Acknowledgment. We thank Fundação para a Ciência e Tecnologia (FCT), Lisbon, Portugal and to FEDER for financial support to Centro de Investigação em Química, University of Porto. J.I.T.A.C. and J.R.B.G. thank FCT and the European Social Fund (ESF) under the 3rd Community Support Framework (CSF) for the award of Ph.D. (BD/5364/2001) and postdoc (BPD/11582/2002) research grants, respectively.

Supporting Information Available: Schemes used for the estimation of the $\Delta_{298 \mathrm{~K}}^{T} H_{\mathrm{m}}^{\mathrm{o}}$ (g) values; description for combustion measurements and detailed data of each combustion experiment; calibration of the Calvet microcalorimeter and microcalorimetric standard enthalpies of vaporization, at $T=298.15 \mathrm{~K}$; full-optimized geometries and enthalpies, at $T=298.15 \mathrm{~K}$; and ${ }^{1} \mathrm{H}$ - and ${ }^{13} \mathrm{C}$ NMR data of cis-2,6-dimethylpiperidine and 3,5-dimethylpiperidine. This material is available free of charge via the Internet at http://pubs.acs.org.

JO052468W

(59) Frisch, M. J.; Trucks, G. W.; Schlegel, H. B.; Scuseria, G. E.; Robb, M. A.; Cheeseman, J. R.; Zakrzewski, V. G.; Montgomery, J. A., Jr.; Stratmann, R. E.; Burant, J. C.; Dapprich, S.; Millan, J. M.; Daniels, A. D.; Kudin, K. N.; Strain, M. C.; Farkas, O.; Tomasi, J.; Barone, V.; Cossi, M.; Cammi, R.; Mennucci, B.; Pomelli, C.; Adamo, C.; Clifford, S. Ochterski, J.; Petersson, G. A.; Ayala, P. Y.; Cui, G.; Morokuma, K.; Malick, D. K.; Rabuck, A. D.; Raghavachari, K.; Foresman, J. B.; Cioslowski, J.; Ortiz, J. V.; Stefanov, B. B.; Liu, G.; Liashenko, A.; Piskorz, P.; Komaromi, I.; Gomperts, R.; Martin, R. L.; Fox, D. J.; Keith, T.; Al-Laham, M. A.; Peng, C. Y.; Nanayakkara, A.; Gonzalez, C.; Challacombe, M.; Gill, P. M. W.; Johnson, B.; Chen, B.; Wong, M. W.; Andres, J. L.; Head-Gordon, M.; Replogle, E. S.; Pople, J. A. Gaussian 98, revision A.9; Gaussian, Inc.: Pittsburgh, PA, 1998 